\title{
Improving Pedagogy Through The Use Of Dynamic Excel Presentations In Financial Management Courses
}

\author{
George A. Mangiero, PhD, Iona College, USA \\ John Manley, PhD, Iona College, USA \\ J. T. Mollica, Boston University, USA
}

\begin{abstract}
This paper discusses and illustrates the use of dynamic Excel presentations to improve learning in Financial Management courses. Through the use of such presentations, multiple and varied examples of important principles in Financial Management, which would ordinarily take an excessive amount of time to cover, can be considered within the time span of a single class. Two applications of these techniques are presented in this paper: (1) Time Value of Money -- Classic Retirement Annuity analysis and (2) Capital Structure Decisions -- EBIT-EPS Analysis. By using these Excel techniques to cover multiple examples under different initial conditions and assumptions, the authors contend that students gain a broader understanding of these financial problems and their solutions, than would otherwise be possible.
\end{abstract}

Keywords: Excel, Pedagogy, Time Value of Money, Retirement Annuities, Capital Structure, Financial Management, Technology in the Classroom.

\section{INTRODUCTION}

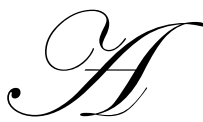

$\mathrm{s}$ is true in every course of study, knowledge of the problems involved in Financial Management and of their potential solutions is transferred through the presentation of abstract principles followed by illustrative examples of how these principles are applied in real business situations. Often the quality of such presentations is improved by considering multiple and varied examples associated with a single principle. Multiple examples give students the opportunity to view a problem from a range of perspectives, the cumulative effect of which enables them to acquire a more comprehensive understanding of the topic under discussion.

Unfortunately, limited classroom time often prevents the presentation of more than just one or two basic examples of the application of any particular principle. This is true for a variety of reasons, perhaps the most obvious of which is the fact that the solution of many problems requires multi-step calculations involving several variables to arrive at a result. Illustrating these mechanical steps once is important. However, repeating them many times to demonstrate the effect of changing various subsets of the input variables - a sensitivity analysis of sorts - if not impossible, can be a tedious waste of classroom time. Also, those students who struggle with quantitative material may get stuck on a difficult computation, which can be worked out afterwards, when they ought to be focusing on the principle.

The increasing use of technology in the classroom has significantly reduced the magnitude of this problem in many ways. Taking advantage of this technology, the authors have developed a set of unique dynamic Excel presentations for use in a Financial Management course. Two such presentations are discussed in this paper. The topics covered in these two presentations are: 
I. Time Value of Money: Classic Retirement Annuity

II. Capital Structure: EBIT - EPS Analysis

We intend to demonstrate how these presentations substantially improve classroom pedagogy by accomplishing the following:

- $\quad$ They provide better use of classroom time by trading off mechanical computational work for conceptual understanding.

- They allow for a broader more thorough coverage of the principle being discussed, since they offer the possibility of presenting more than a hundred examples of a single principle in just one session.

- They provide, in a way that, for example, overhead transparencies cannot, a rich understanding of the interrelationships among the various parameters in the model.

The dynamic aspect of these presentations is perhaps their most compelling feature. The quick manipulation of the various parameters in the models we discuss and the effect of these manipulations on the output of the model is quite persuasive. The visual layout of the presentations is another strong point. Through the use of several visual effects, such as color-coding, the information that the students view in each spreadsheet gives them a broad overview of the problem and its solution.

There are, of course, many other topics in Financial Management for which this kind of dynamic Excel presentation would be appropriate. We plan to develop a more extensive series of these models. For example, one covering Capital Budgeting: NPV Sensitivity Analysis and another on the topic of Fixed Income Analysis: Bond Duration and Convexity. We chose this sample of two (1) because we believe that they are representative of the various techniques that can be built into any such presentation, (2) because they were interesting to us, and (3) because they have already been classroom tested.

In discussing these two presentations, we will first describe the Financial Management issue being studied and identify the problem to be solved. Next we will show how the issue is addressed and the problem solved in the various Excel spreadsheets. Finally, we will explain the pedagogical benefits achieved in each case.

\section{Time Value of Money: Classic Retirement Annuity}

The problem to be solved here is stated as follows:

Suppose an investor wishes to set up a retirement annuity by making equal semiannual deposits into an account, which offers an annual stated rate of 12 percent per year compounded semiannually. The first of these semiannual deposits will be made on his $25^{\text {th }}$ birthday and the last on his $45^{\text {th }}$ birthday. His goal is to be able to make annual withdrawals of $\$ 50,000$ when he retires starting on his $65^{\text {th }}$ birthday and continuing to his $85^{\text {th }}$ birthday, inclusive. Assume that the account continues to offer 12 percent per year compounded semiannually throughout the entire period of deposits and withdrawals. What must be the necessary and sufficient amount of the semiannual deposits, if this goal is to be achieved?

The solution to this problem involves three steps (five, if you count the calculation of $\mathrm{k}_{\text {peff }}$ in steps 1 and 3 as additional steps):

Step 1. Determine the total amount that must be on deposit on the day that the first withdrawal of $\$ 50,000$ is to be made, such that the investor will be able to make this withdrawal and the remaining 20 withdrawals. This can be calculated with the following formula.

$\mathrm{PVA}_{\mathrm{t}}^{\mathrm{D}}=\mathrm{a}\left(\left(1-\left(1+\mathrm{k}_{\text {peff }}\right)^{-\mathrm{pt}}\right) / \mathrm{k}_{\text {peff }}\right)\left(1+\mathrm{k}_{\text {peff }}\right)$ 
where $\mathrm{PVA}^{\mathrm{D}}{ }_{\mathrm{t}}=$ the present value of an annuity due

$\mathrm{a}=$ the annuity amount $(\$ 50,000$ in this case)

$\mathrm{k}_{\text {peff }}=$ the effective rate per payment period $=(1+(\mathrm{r} / \mathrm{c}))^{\mathrm{c} / \mathrm{p}}-1$

$r=$ the stated annual rate of interest $(r=12$ percent $)$

$\mathrm{c}=$ the number of compounding periods per year $(\mathrm{c}=2)$

$\mathrm{p}=$ the number of payments per year $(\mathrm{p}=1$ in this case $)$

and $\quad t=$ the number of years $(t=21$ in this case $)$.

$\mathrm{k}_{\text {peff }}=(1+(\mathrm{r} / \mathrm{c}))^{\mathrm{c} / \mathrm{p}}-1=(1.06)^{2 / 1}-1=0.1236$

Thus,

$\mathrm{PVA}^{\mathrm{D}}{ }_{\mathrm{t}}=\mathrm{a}\left(\left(1-\left(1+\mathrm{k}_{\text {peff }}\right)^{-\mathrm{pt}}\right) / \mathrm{k}_{\text {peff }}\right)\left(1+\mathrm{k}_{\text {peff }}\right)$

$=\$ 50,000\left(\left(1-(1.1236)^{-21}\right) / 0.1236\right)(1.1236)=\$ 415,201.38$

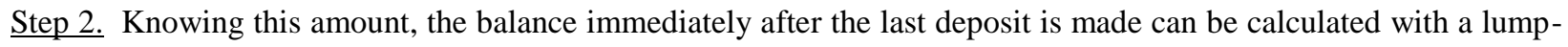
sum PV calculation, as follows:

$\mathrm{PV}=\mathrm{FV}_{\mathrm{t}} /(1+(\mathrm{r} / \mathrm{c}))^{\mathrm{ct}}$

where $\quad P V=$ the present value

$\mathrm{FV}_{\mathrm{t}}=$ the future value $\mathrm{t}$ years from the present

and $\quad \mathrm{r}, \mathrm{c}$, and $\mathrm{t}$ are defined as above.

$\mathrm{FV}_{\mathrm{t}}$ is the amount calculated in Step $1=\$ 415,201.38$. Thus,

Thus,

$\mathrm{PV}=\$ 415,201.38 /(1.06)^{(2)(20)}=\$ 40,366.79$

This tells us that on the investor's $45^{\text {th }}$ birthday, the day of his last semiannual deposit, the account balance must be $\$ 40,366.79$. This amount will then remain on deposit for the next 20 years, earning interest, and will grow to the balance of $\$ 415,201.38$ needed on the investor's $65^{\text {th }}$ birthday.

Step 3. This $\$ 40,366.79$ figure can now be used to determine the amount of the 41 equal deposits, since it becomes, in this step, the future value of an ordinary annuity - the series of 41 semiannual deposits. We use the following formula to calculate the deposit amounts:

$\mathrm{FVA}_{\mathrm{t}}=\mathrm{a}\left(\left(\left(1+\mathrm{k}_{\text {peff }}\right)^{\mathrm{pt}}-1\right) / \mathrm{k}_{\text {peff }}\right)$

where $\quad \mathrm{FVA}_{\mathrm{t}}=$ the future value of an ordinary annuity

$\mathrm{a}=$ the annuity amount $=$ the unknown deposit amount

$\mathrm{k}_{\text {peff }}=$ the effective rate per payment period $=(1+(\mathrm{r} / \mathrm{c}))^{\mathrm{c} / \mathrm{p}}-1$

$r=$ the stated annual rate of interest $(r=12$ percent $)$

$\mathrm{c}=$ the number of compounding periods per year $(\mathrm{c}=2)$

$\mathrm{p}=$ the number of payments per year $(\mathrm{p}=2$ in this case)

and $\quad t=$ the number of years $(t=20.5$ in this case).

$\mathrm{k}_{\mathrm{peff}}=(1+(\mathrm{r} / \mathrm{c}))^{\mathrm{c} / \mathrm{p}}-1=(1.06)^{2 / 2}-1=0.06$

Notice that the value of $\mathrm{k}_{\text {peff }}$ is not the same as in Step 1, since the payment period is now 0.5 years instead of 1 year.

Thus,

$\$ 40,366.79=\mathrm{a}\left(\left((1.06)^{41}-1\right) / .06\right)$

Solving for $\mathrm{a}$, we get $\mathrm{a}=$ the deposit amount $=\$ 244.58$. 
For most students, this is a surprisingly small amount. It is small, however, because the investor started saving on is $25^{\text {th }}$ birthday instead later in life. How much smaller would it have been, if, for example, he had started saving on his $21^{\text {st }}$ birthday and continued until age 50. What about the interest rate? How sensitive is this answer to increases or decreases in the annual stated rate of interest, $r$ ? Also, what if a larger withdrawal is desired? Finally, what if we ask how much would the investor be able to withdraw for a given fixed deposit amount? To answer all these questions, and many more, we could of course repeat the calculations in Steps 1-3 numerous times - once for each new question. But this would be too time consuming.

Instead the authors designed an Excel spreadsheet to answer all these questions in mere seconds.

Figure 1 shows the layout of the spread sheet with the relevant variables set to coincide with the values given in the problem above. Notice that the specified semiannual deposits are $\$ 244.58$ - the amount calculated above.

Notice, also, that there are five parameters that can be changed to see their effect: (1) the stated rate of interest, (2) the age of the first deposit, (3) the age of the last deposit, (4) the amount of the desired withdrawal during the retirement years, and (5) whether the deposit amount is calculated for a given withdrawal amount, or the withdrawal amount is calculated for a given deposit amount. Thus, having done the calculation once, hundreds of other possibilities can be explored and discussed in a matter of minutes. Three examples should suffice.

In Figure 2, the interest rate has been lowered to 8 percent per year, with the resulting semiannual deposits increasing to $\$ 1,116.53$. This illustrates how highly sensitive these deposit amounts are to changes in the annual stated interest rate.

In Figure 3, with the interest rate returned to 12 percent, the age of the first deposit is increased to 40 instead of 25 . For the same set of $\$ 50,000$ withdrawals during the retirement years, the deposits would have to increase to $\$ 2,696.22$. This illustrates the importance of starting to save early in life and usually grabs the attention of the students in a dramatic way.

Finally, suppose a student wanted to know what his retirement withdrawals would be, if he were to start saving at age 20, using an interest rate of 8 percent per year, and depositing $\$ 1,200$ semiannually (roughly the equivalent of $\$ 200$ per month). This question is easily answered by changing the settings, as illustrated in Figure 4. The withdrawal amounts would be $\$ 86,008.53$.

\section{Capital Structure: EBIT - EPS Analysis}

The problem here is to choose, from among three possible financing options, the option which maximizes EPS in an elementary example, to then illustrate the sensitivity of the choice to changes in EBIT, and finally to examine the probability that the choice will be correct knowing something about the statistical distribution of EBIT.

The elementary problem is given as follows:

Suppose that XYZ Corporation's current balance sheet is as follows:

$\begin{array}{lllr}\text { Current Assets } & \$ 5,000,000 & \text { Debt } & \$ 0 \\ \text { Net Fixed Assets } & \underline{\$ 5,000,000} & \text { Preferred Stock } & \$ 0 \\ & & \text { Common Stock } & \$ 10,000,000 \\ \text { Total Assets } & \underline{\$ 10,000,000} & \text { Total Claims } & \underline{\$ 10,000,000}\end{array}$

Let the tax rate, $T=40$ percent, the number of common shares outstanding $=200,000$ shares, and the book value (BV) and market value (MV) of the common stock $=\$ 50 /$ share.

Suppose, also, that $\mathrm{XYZ}$ wants to raise another $\$ 5,000,000$ for expansion, and is considering just the following three options, from a vast multitude of choices, to finance the expansion: 
Plan A: Finance the entire amount with common stock (C/S) only => Issue 100,000 new shares of C/S.

Plan B: Finance the entire amount with debt (D) only, at $\mathrm{k}_{\mathrm{D}}=12$ percent interest.

Plan C: Finance the entire amount with preferred stock $(\mathrm{PFD})$ only, offering a preferred dividend $(\mathrm{PD})$ of $\mathrm{k}_{\mathrm{PFD}}=11$ percent.

Suppose, finally, that EBIT is forecasted to be $\$ 2,400,000$.

Now,

$\mathrm{EPS}=[(\mathrm{EBIT}-\mathrm{I})(1-\mathrm{T})-\mathrm{PD}] / \mathrm{N}$

where $\mathrm{N}=$ the number of common shares outstanding.

For Plan A, the C/S plan, $\mathrm{I}=\$ 0, \mathrm{PD}=\$ 0$, and $\mathrm{N}=300,000$. Then,

$\mathrm{EPS}^{\mathrm{A}}=[(\$ 2,400,000-\$ 0)(1-.40)-\$ 0] / 300,000=\$ 4.80$.

For Plan B, the Debt plan, $\mathrm{I}=\$ 600,000, \mathrm{PD}=\$ 0$, and $\mathrm{N}=200,000$. Then,

$\operatorname{EPS}^{\mathrm{B}}=[(\$ 2,400,000-\$ 600,000)(1-.40)-\$ 0] / 200,000=\$ 5.40$.

For Plan C, the PFD plan, $\mathrm{I}=\$ 0, \mathrm{PD}=\$ 550,000$, and $\mathrm{N}=200,000$. Then,

$\operatorname{EPS}^{\mathrm{C}}=[(\$ 2,400,000-\$ 0)(1-.40)-\$ 550,000] / 200,000=\$ 4.45$.

Under these circumstances, with EBIT $=\$ 2,400,000$, and considering only these three plans, the plan with the highest EPS is plan B - the Debt plan. Note that $\mathrm{EPC}^{\mathrm{B}}$ exceeds $\mathrm{EPS}^{\mathrm{C}}$ by $\$ 0.95$.

The question now becomes, how confident are we in the forecast of EBIT $=\$ 2,400,000$. Suppose we are not $100 \%$ confident.

With this in mind, we now suggest that students try two additional EBIT possibilities - EBIT $=\$ 1,100,000$ and $\mathrm{EBIT}=\$ 3,000,000$. However, rather than repeating the calculations above, we present the Excel spreadsheet shown in Figure 5.

In this spread sheet, there is one column for each of the three plans and EPS is calculated near the bottom of each column in the same manner as was done using the formula above.

First, interest (consisting of both $\mathrm{I}_{\mathrm{OLD}}$ and $\mathrm{I}_{\mathrm{NEW}}$, where $\mathrm{I}_{\mathrm{OLD}}$ is interest on any debt already in the capital structure, and $\mathrm{I}_{\mathrm{NEW}}$ is interest that will be incurred if a plan calls for using debt) is subtracted from EBIT. Then, taxes are subtracted to arrive at earnings after taxes, EAT. Here, we check the first box on the right which shows these calculations and brings up the results for EAT for all three plans. See Figure 6.

Next, we explain that these earnings are not the earnings available to the common shareholders, if there are preferred dividends to be paid. Thus, the next line in the table shows preferred dividends being subtracted from EAT. We check the second box on the right to show how this affects plan C, the PFD plan, but not plans A and B. See Figure 7 , where $\mathrm{E}_{\mathrm{AVAIL}}$ is defined as earnings available to the common shareholders.

Finally, we check the last box on the right which shows $\mathrm{E}_{\mathrm{AVAIL}}$ being divided by $\mathrm{N}$, the number of common shares outstanding, and the resulting EPS. Also displayed, at this point are the rankings from highest to lowest EPS and the fact that $\mathrm{EPC}^{\mathrm{B}}$ exceeds $E P S^{\mathrm{C}}$ by $\$ 0.95$, in this example. See Figure 8. 
In this last figure, notice the spinner in the upper left corner, which allows us to quickly change the value of EBIT in steps of $\$ 50,000$ from $\$ 0$ to $\$ 9,000,000$. So, we simply reduce EBIT to $\$ 1,100,000$ and then increase it to $\$ 3,000,000$ to show that, in fact, the plan choice depends on EBIT. See Figures 9 and 10. With EBIT $=\$ 1,100,000$, Plan $\mathrm{A}-$ the $\mathrm{C} / \mathrm{S}$ plan - has the highest EPS. However, with EBIT $=\$ 3,000,000$, the plan with the highest EPS is again plan $\mathrm{B}-$ the Debt plan. In both cases, $\mathrm{EPC}^{\mathrm{B}}$ still exceeds EPS ${ }^{\mathrm{C}}$ by $\$ 0.95$.

We now vary EBIT over a wide range of values to show that, for some values of EBIT, Plan A has the highest EPS and, for others, Plan B has the highest EPS, but that $\mathrm{EPC}^{\mathrm{B}}$ always exceeds EPS ${ }^{\mathrm{C}}$ by $\$ 0.95$. Thus, Plan $\mathrm{C}$ will never be the plan of choice.

Once these concepts are clear, we switch to a presentation where these results are presented graphically, in a plot of EPS versus EBIT - a linear relationship. See Figure 11. Notice that there are multiple spinners at the left, which allow us to change every significant parameter in the problem, such as the amount of the investment to be financed, $\mathrm{I}_{0}$, the tax rate, the interest on the debt, the preferred dividend rate, and the price of the stock.

Keeping these parameters set at the levels in the original problem presented above, we first check the top box on the right, which displays the graph for the debt plan. This is a graph of the equation for the debt plan given as follows (See Figure 12):

$\mathrm{EPS}^{\mathrm{B}}=[(\mathrm{EBIT}-\$ 600,000)(1-.40)-\$ 0] / 200,000$

Displayed are all values of $\mathrm{EPS}^{\mathrm{B}}$ as EBIT varies from $\$ 0$ to $\$ 4,000,000$. The EPS intercept is $\$-1.80$.

Next, we check the third box on the right, which displays the graph for the preferred stock plan. This is a graph of the equation for the preferred stock plan given as follows (See Figure 13):

EPS $^{\mathrm{C}}=[(\mathrm{EBIT}-\$ 0)(1-.40)-\$ 550,000] / 200,000$

We point out that these two lines are parallel (they have the same slope which equals $0.60 / 200,000$ ) and that the EPS intercept for the Preferred stock plan is at $\$-2.75$, exactly $\$ 0.95$ below the EPS intercept for the debt plan. Thus, the debt plan will always dominate the preferred stock plan, and the latter need no longer be considered.

We then uncheck the third box and check the second box, which displays the graph for the C/S plan. This is a graph of the equation for the C/S plan given as follows (See Figure 14):

$\mathrm{EPS}^{\mathrm{A}}=[(\mathrm{EBIT}-\$ 0)(1-.40)-\$ 0] / 300,000$

The important point to note here is that the plotted lines intersect. Thus, for some values of EBIT the C/S plan results in a higher EPS but for other values of EBIT the debt plan results in a higher EPS. In other words, the two graphs cross each other and the EBIT value at which they cross (EBIT*) is the solution to the following equation :

$\left(\right.$ EBIT $\left.^{*}\right)(.60) / 300,000=\left(\right.$ EBIT $\left.^{*}-\$ 600,000\right)(.60) / 200,000$.

Solving this equation, we get

EBIT $*=\$ 1,800,000$, as shown at the lower left in Figure 14.

Selecting the fourth box on the right, simply highlights, which is the preferred plan at all levels of EBIT. See Figure 15.

Finally, we ask the students to consider that fact that forecasted EBIT is not a certainty. We introduce an element of statistical analysis, by asking the students to determine the probability that the debt plan will be the 
correct choice if EBIT is normally distributed with a mean, $\mu$, of $\$ 2,000,000$ and a standard deviation, $\sigma$, of $\$ 250,000$. That is, determine:

$\operatorname{Pr}\{$ Debt Plan is the Correct Choice $\}$

Figure 15 shows that the Debt plan is the correct choice provided that EBIT is greater than $\$ 1,800,000$. Thus, this first probability statement is equivalent to $(\leftrightarrow)$

$$
\begin{array}{ll}
\leftrightarrow & \operatorname{Pr}\{\text { EBIT }>\$ 1,800,000\} \\
\leftrightarrow & \operatorname{Pr}\{(\text { EBIT }-\mu) / \sigma>(\$ 1,800,000-\$ 2,000,000) / \$ 250,000\} \\
\leftrightarrow & \operatorname{Pr}\{\mathrm{z}>-0.80\}, \text { where } \mathrm{z}=(\text { EBIT }-\mu) / \sigma \text { is the standard normal variate. }
\end{array}
$$

This answer can be found by using a normal distribution table or by numerically integrating $\left(1 /(2 \pi)^{1 / 2}\right) \mathrm{e}^{\wedge}(-$ $\mathrm{z}^{2} / 2$ ) from -0.80 to $+\infty$ The answer is $78.81 \%$. Thus, with these values of $\mu$ and $\sigma$, the probability that the debt plan will be the correct choice is $78.81 \%$.

In the final display, see Figure 16, we check the last box on the right. This superimposes a normal curve on the plot, centered at $\mu=\$ 2,000,000$ and with a standard deviation of $\sigma=\$ 250,000$. Also displayed, at the lower right, are the probabilities $\operatorname{Pr}\{z<-0.80\}$ and $\operatorname{Pr}\{z>-0.80\}$, which of course, add to $100 \%$. Students can see that the area under the normal curve to the right of $\$ 1,800,00$ is greater than the area under the curve to the left.

\section{CONCLUSION}

Calculating answers to financial management problems using standard formulas and various mathematical techniques is important to do once or twice, perhaps even several times. But the real goal is to gain a broad understanding of the problem and its solution, which is significantly enhanced by examining multiple examples to illustrate, for example, how sensitive the solution is to various manipulations of the parameters of the problem. With the use of the spreadsheet designs shown in this paper, it is possible to illustrate many different examples in a short period of time, something that it would not be possible to do, if a new calculation had to be performed for each illustrative example.

As mentioned in the introduction, we feel that the dynamic aspect of these presentations is their most compelling feature. The designs - using spinners and true/false flags - allow us to move quickly from one example to the next, making for a much more lively presentation. The visual layout, including the use of color, also makes the presentation more informative and helps focus the attention of the students on the important points being discussed.

\section{AUTHOR INFORMATION}

George A. Mangiero, Ph.D. is an Associate Professor of Finance and Business Economics at Iona College in New Rochelle, New York. He also serves as Director of Study Abroad at Iona. Dr. Mangiero's graduate degrees include an MS in Electrical Engineering from Rensselaer Polytechnic Institute, an MBA in Finance from St. John's University, and an M.Phil. and Ph.D. in Finance from New York University. His research interests are primarily in the areas of Portfolio Management, Financial Futures, Options, and Swaps, and Corporate Finance.He resides with his wife in Connecticut.

John F. Manley, Ph.D. is a Full Professor of Finance in the Hagan School of Business at Iona College and has served as the conference chair for the International Business and Economy Conference for four years. His research interests include mergers and acquisitions, determinants of international firm value, quality management, business education and environmental/sustainability issues. Dr. Manley is actively involved with the Association of Financial Professionals, directing the local chapter on campus, and the Financial Management Association, mentoring the Honors Society on campus. He has published in such journals as Managerial Finance, Quality 
Progress, Journal of Education for Business, and The College Teaching Methods \& Styles Journal. Professor Manley received his Ph.D. from Rutgers University and his MBA from Baruch College.

Jeff Mollica is a Program Manager at Raytheon Company with over 20 years experience. His current activities are focused on program management controls as well as risk management. In addition to his work at Raytheon, Jeff is also an adjunct instructor at the Boston University School of Management, where he has been teaching undergraduate and graduate courses in management decision modeling, managerial economics, and investment management. He has also been involved in corporate finance, economics, and derivatives courses within the executive programs at BU.

\section{REFERENCES}

1. Ross, S. A., Westerfield, R. W., and Jordon, B. D., (2010) Fundamentals of Financial Management, $9^{\text {th }}$ ed., McGraw-Hill, New York, N.Y.

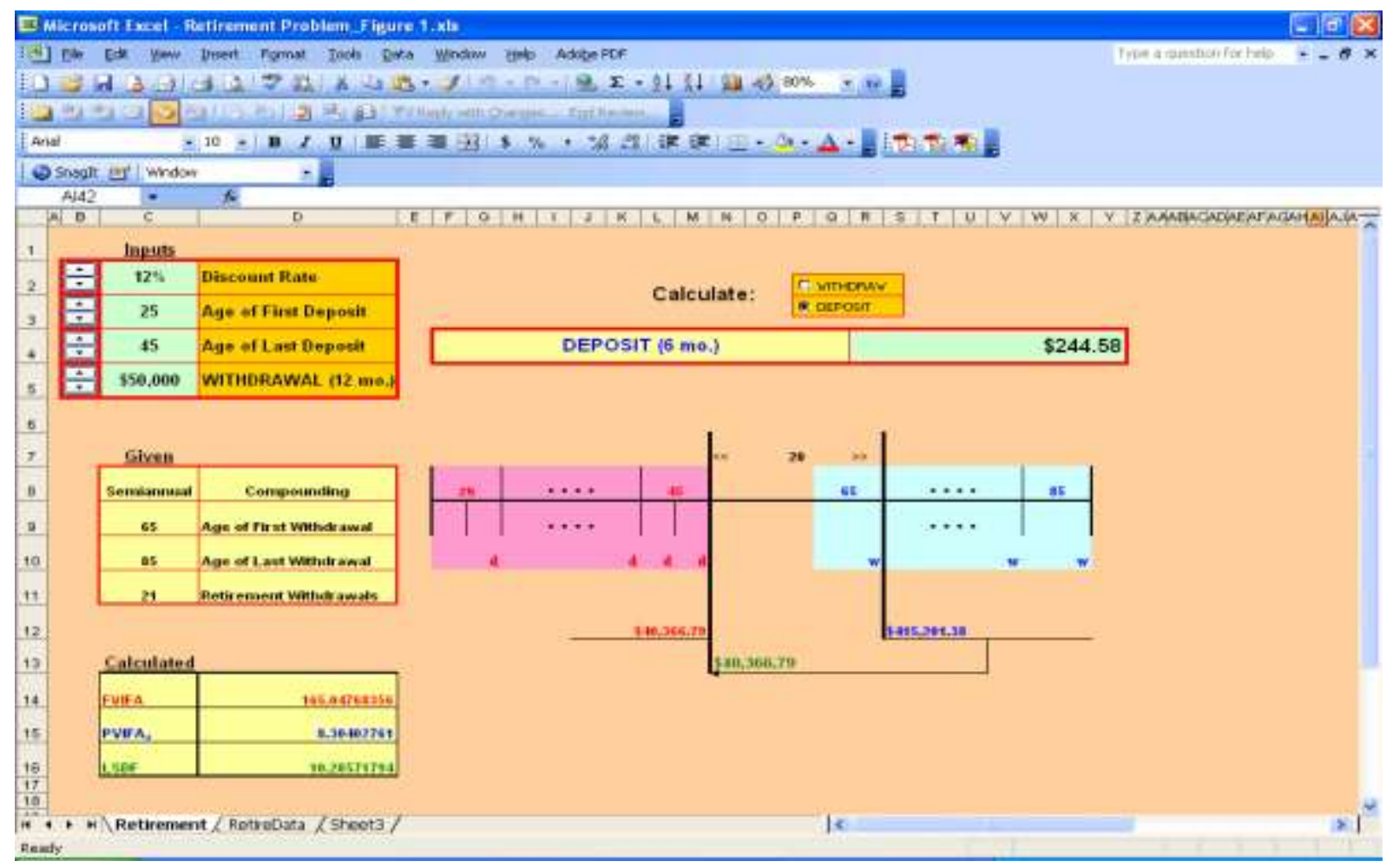

Figure 1 


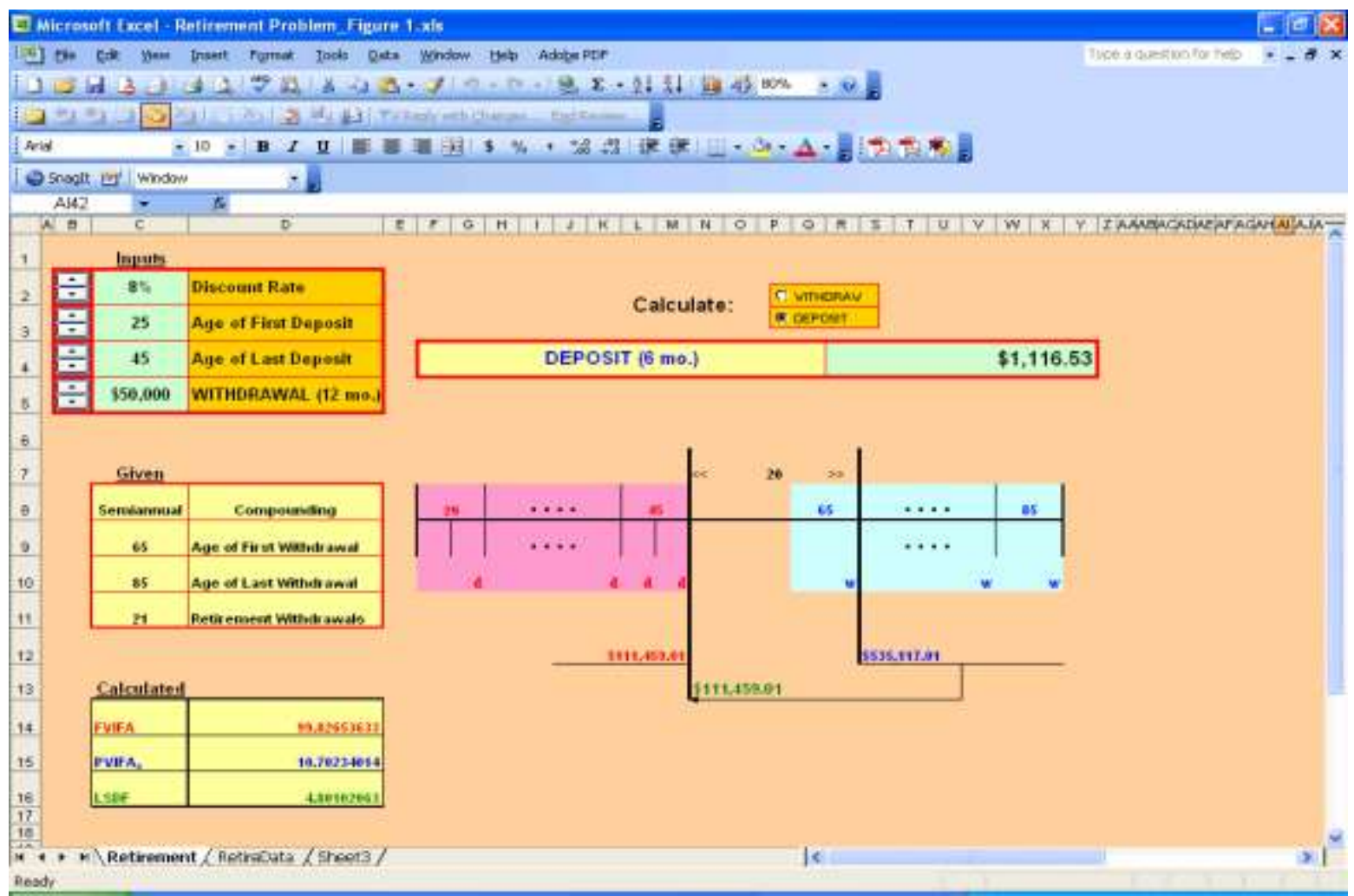

Figure 2

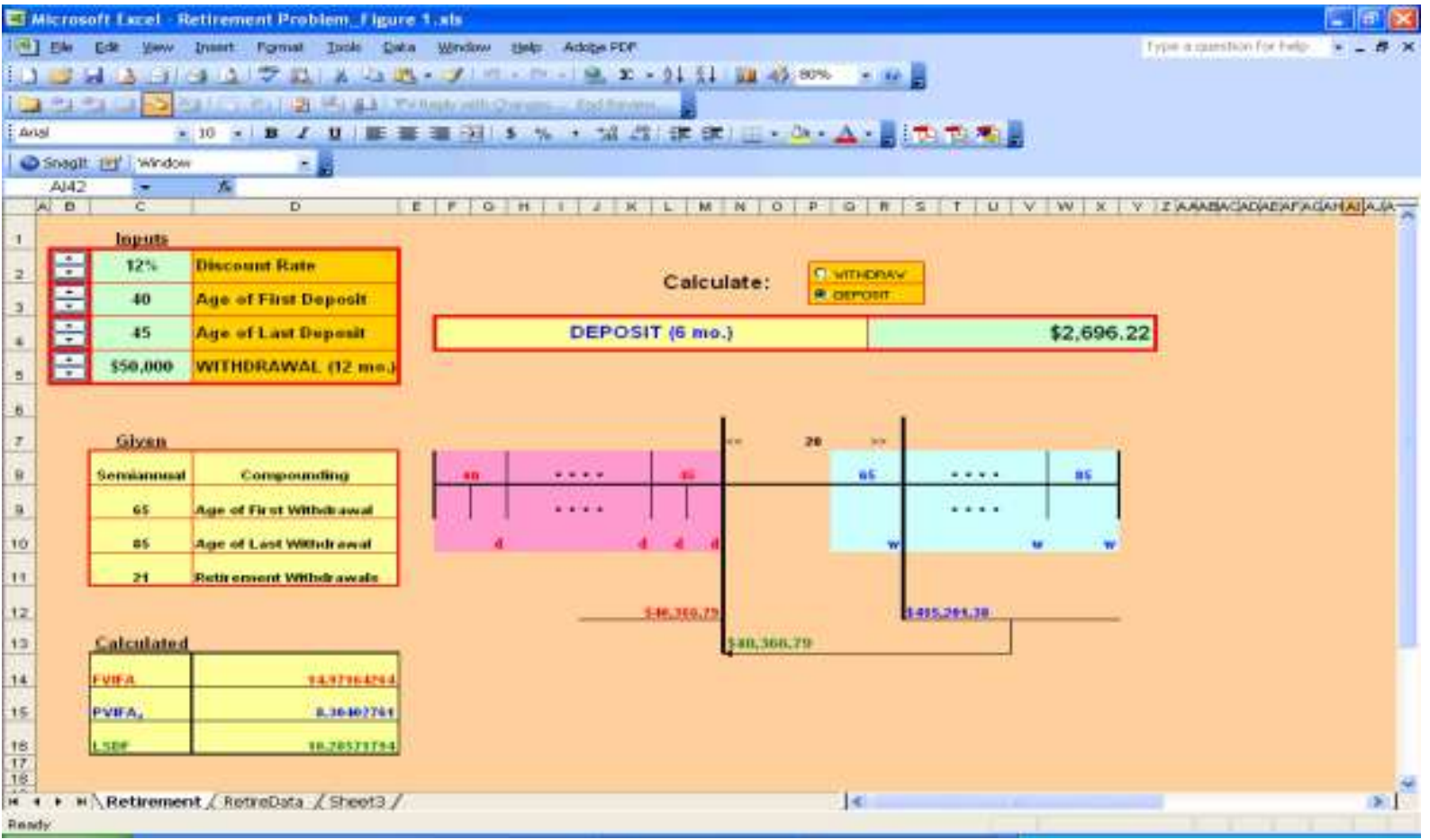

Figure 3 


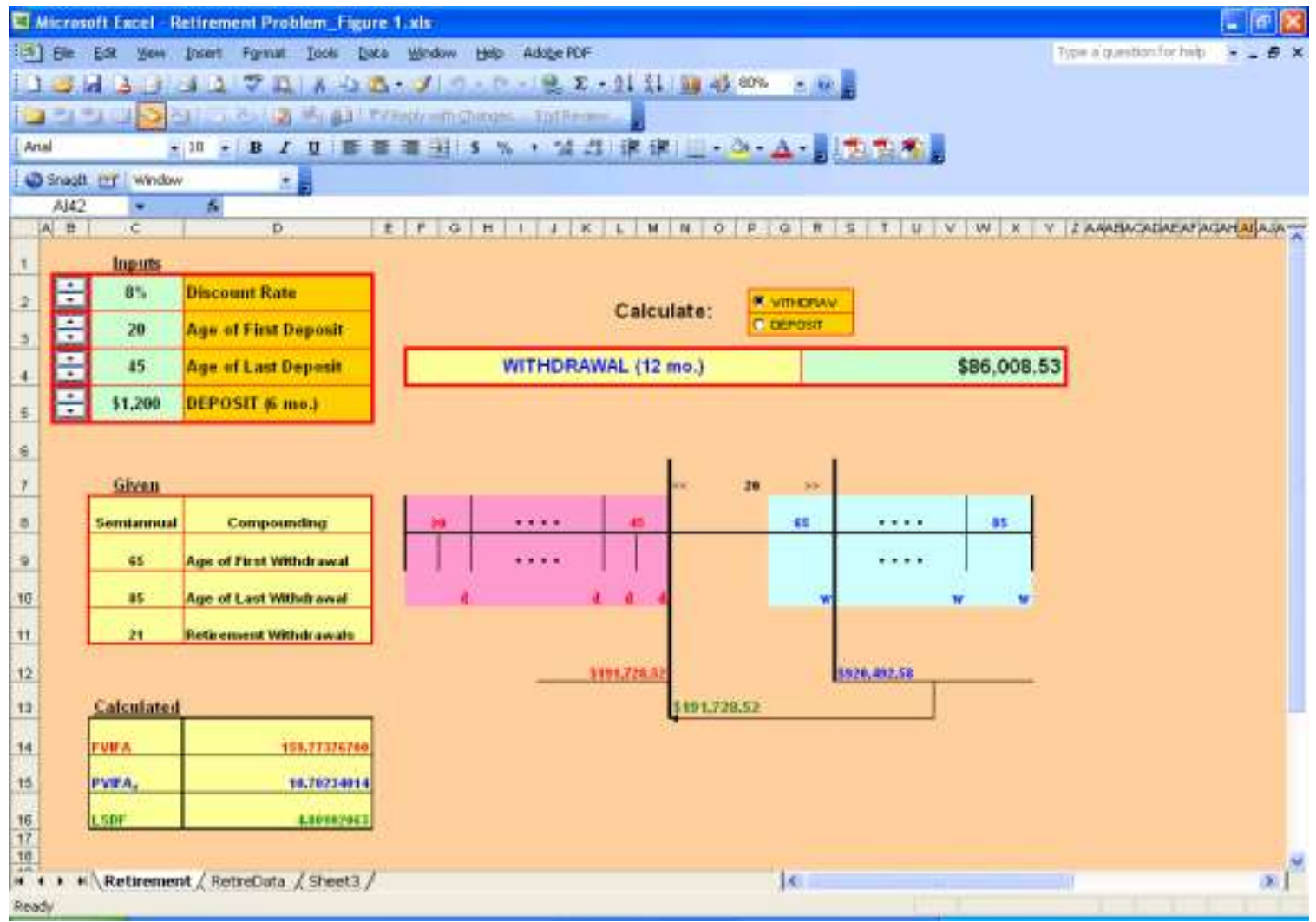

Figure 4

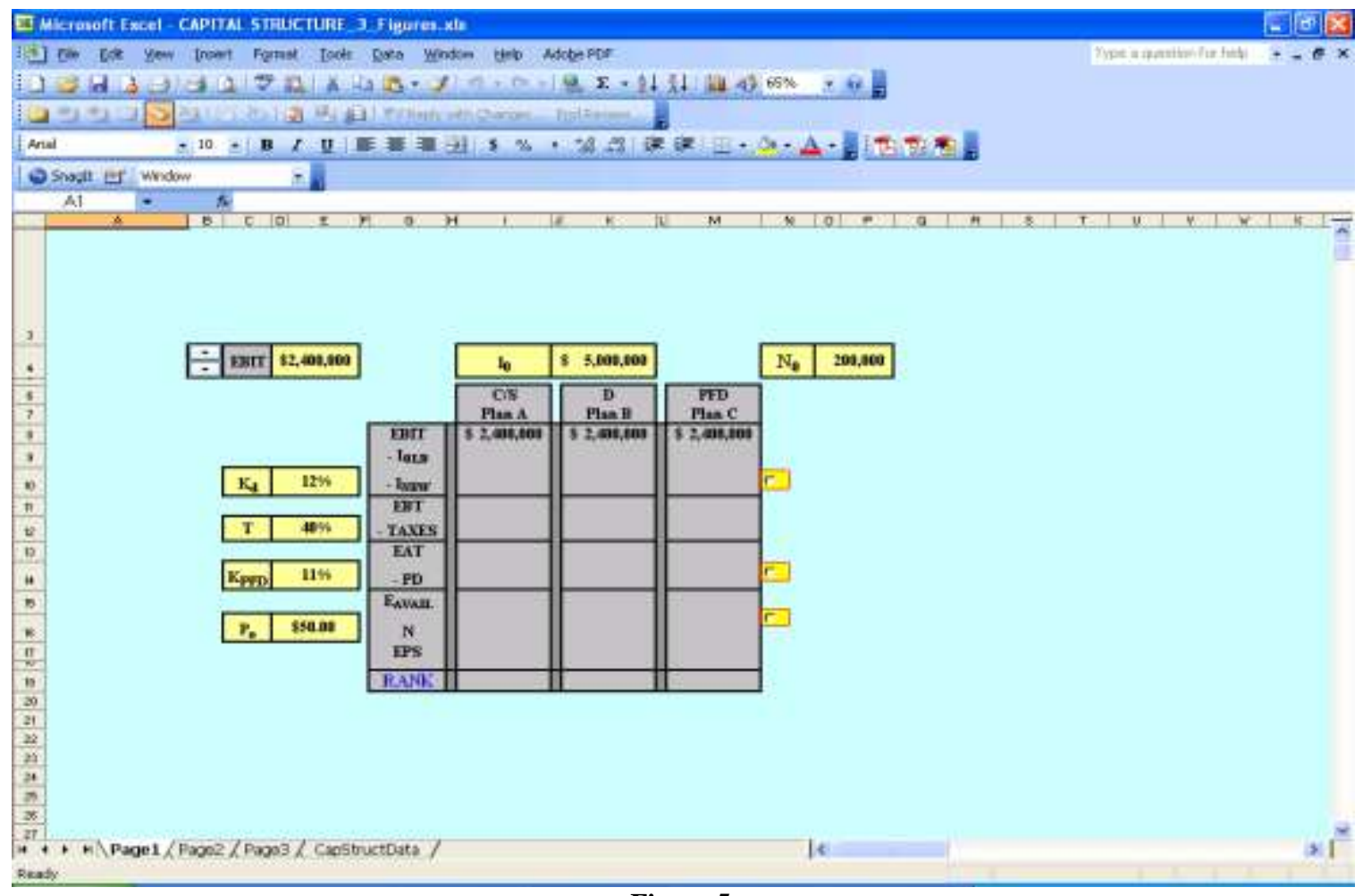

Figure 5 


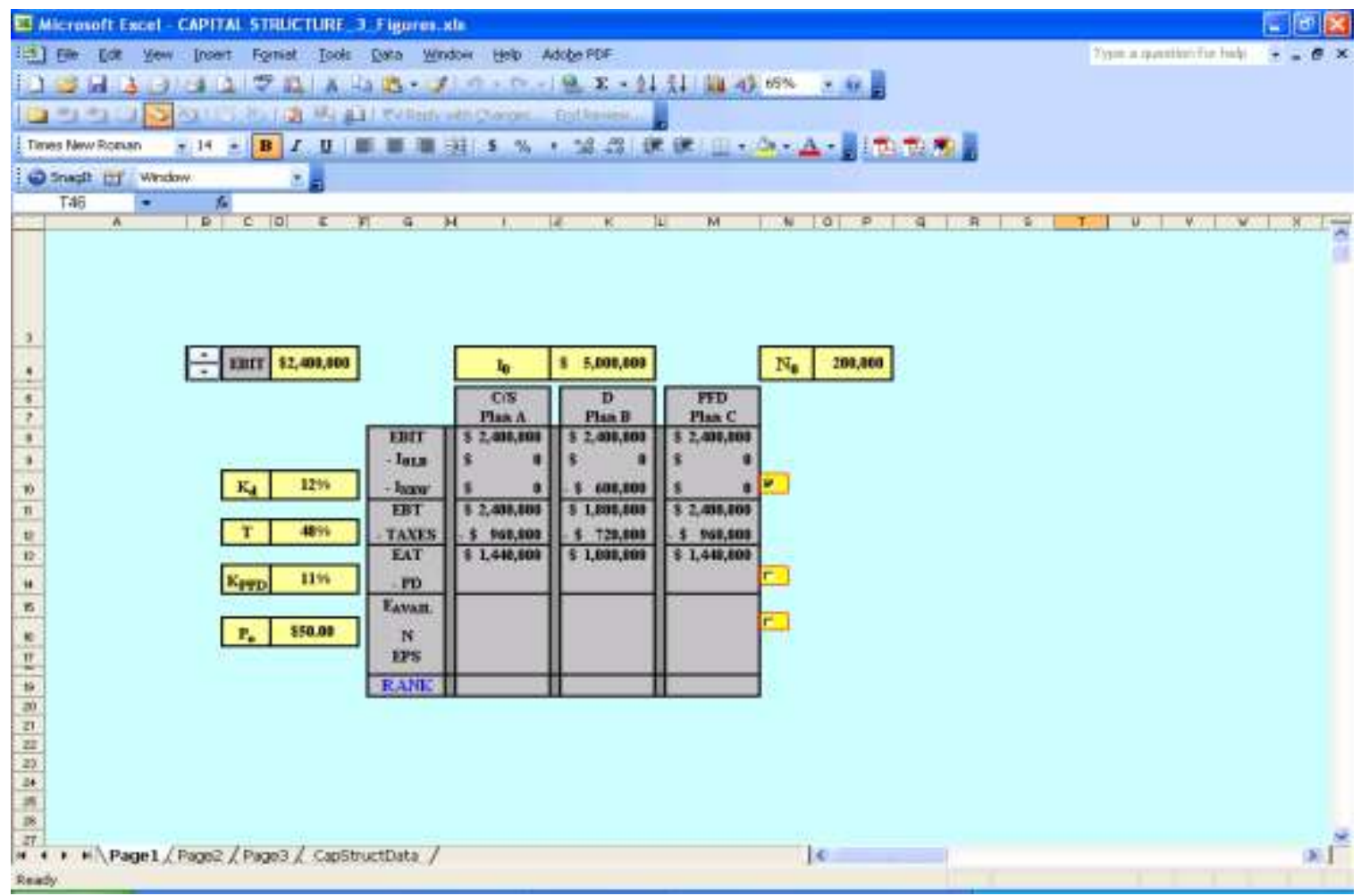

Figure 6

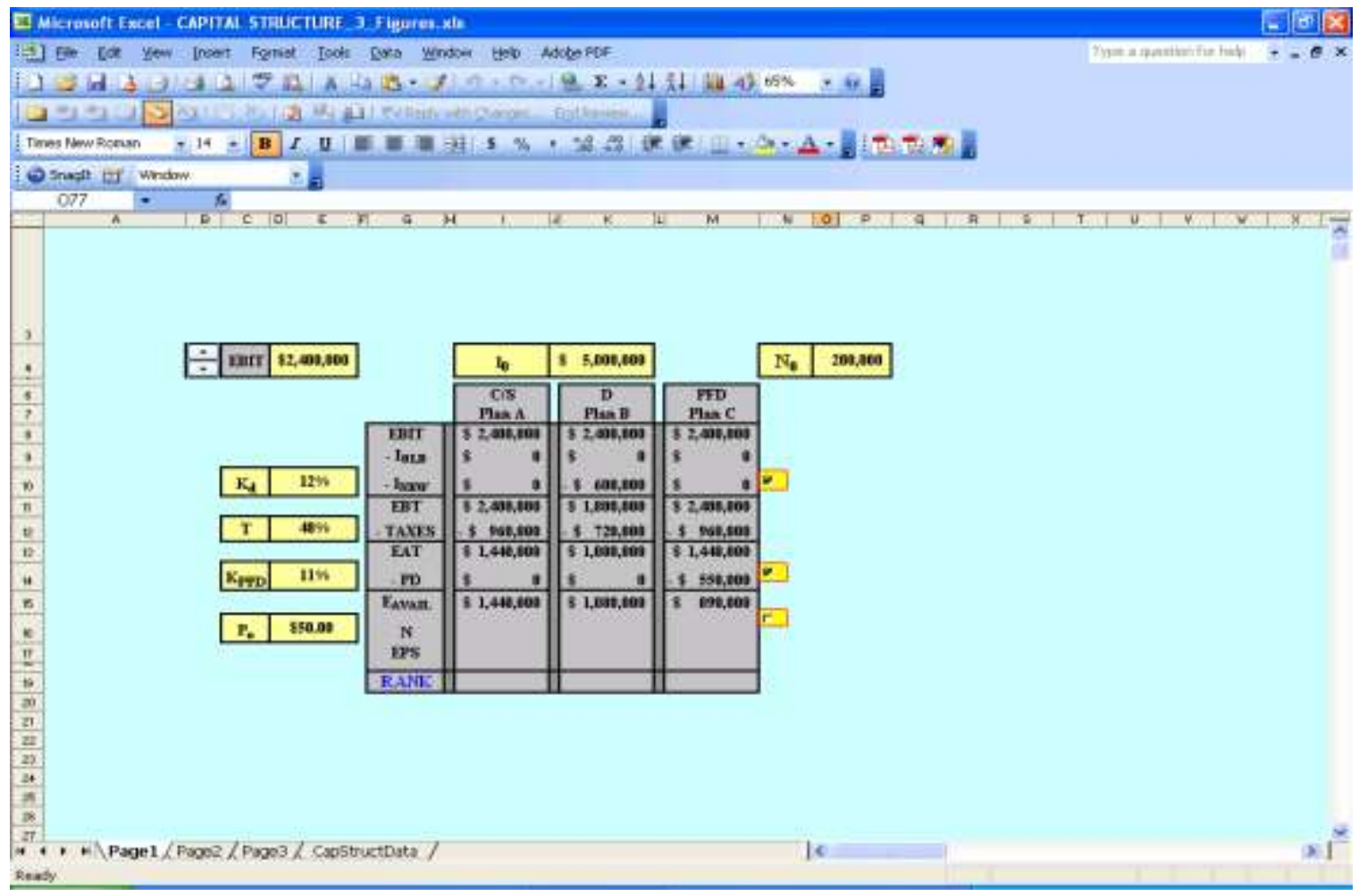

Figure 7 


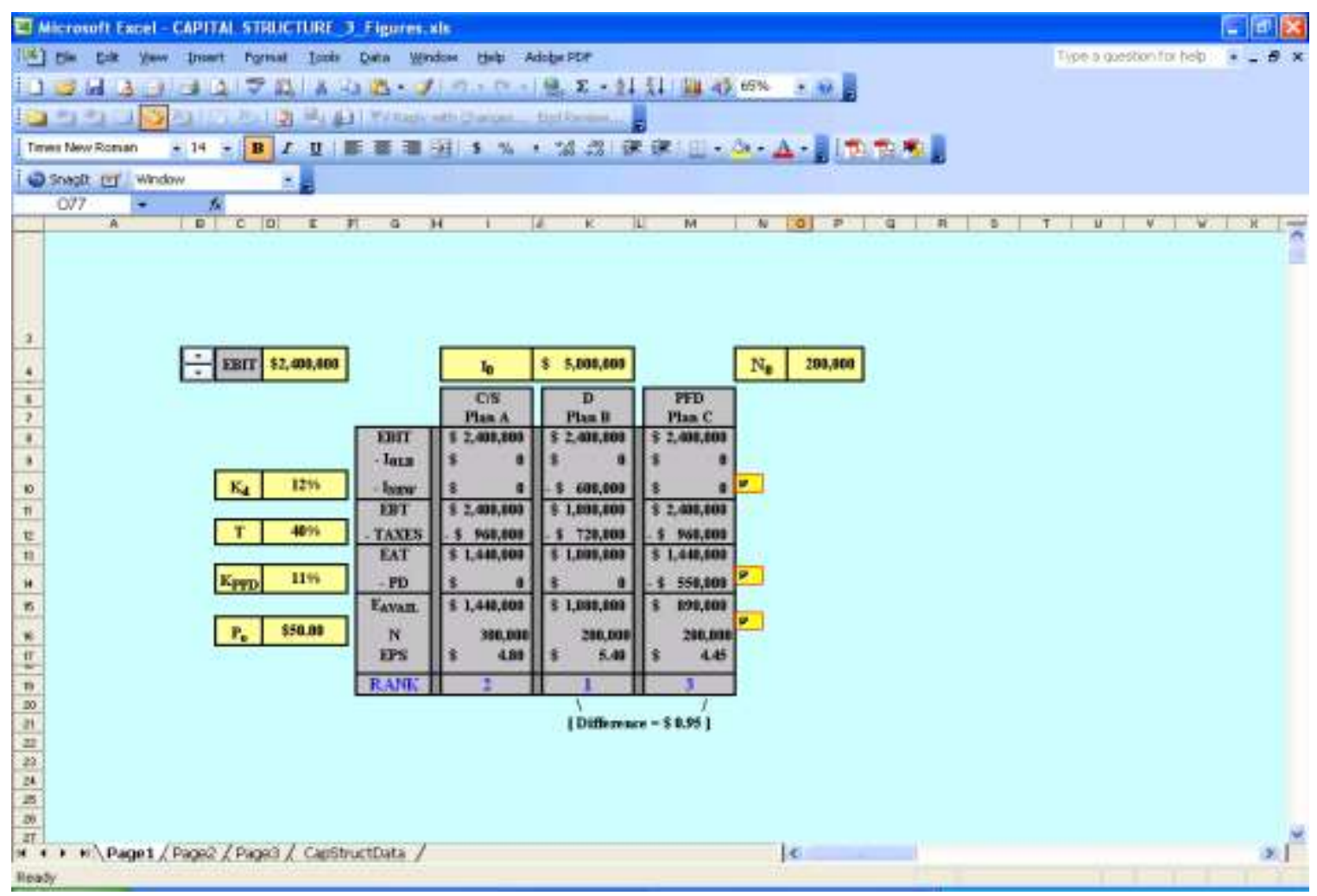

Figure 8

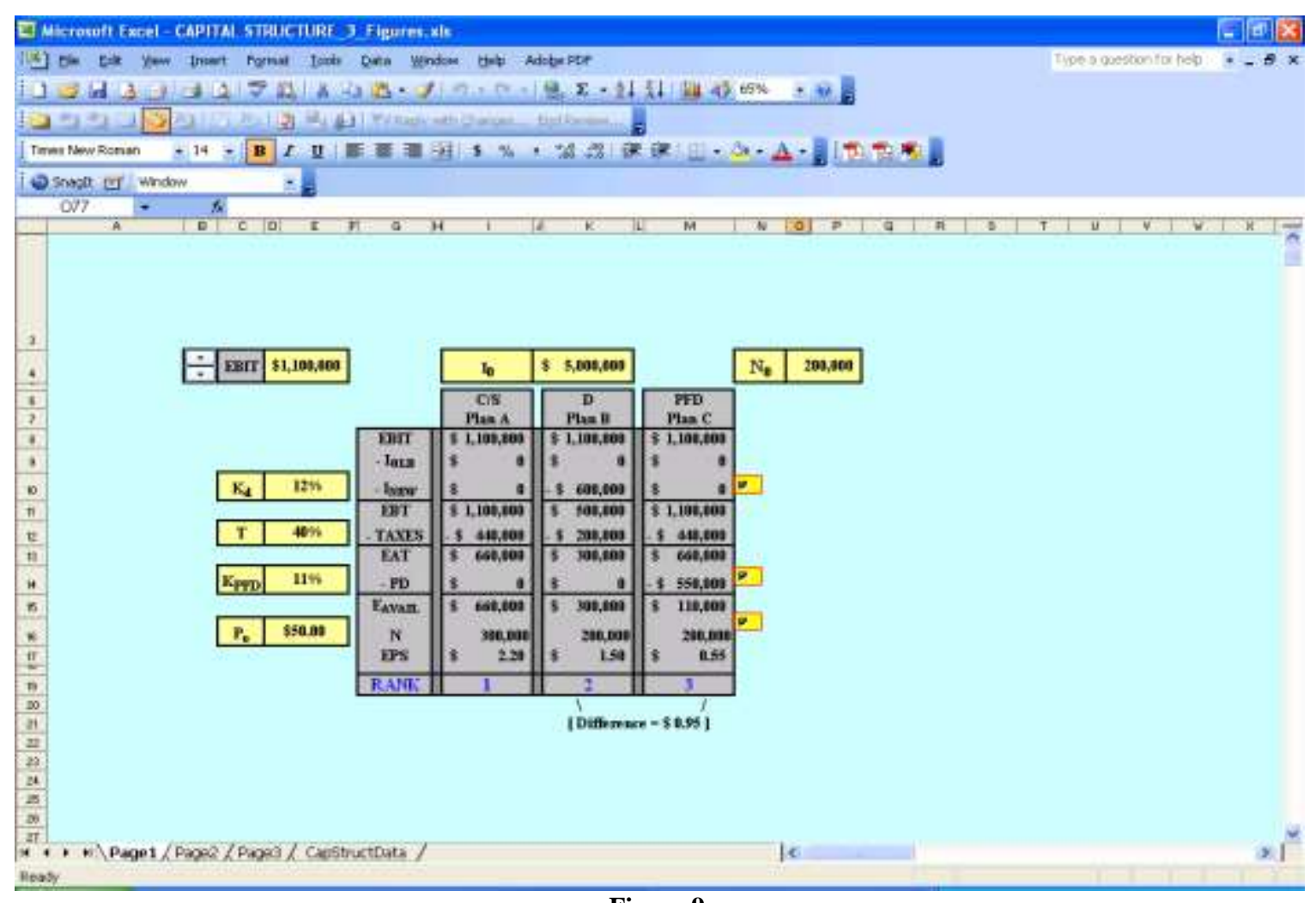

Figure 9 


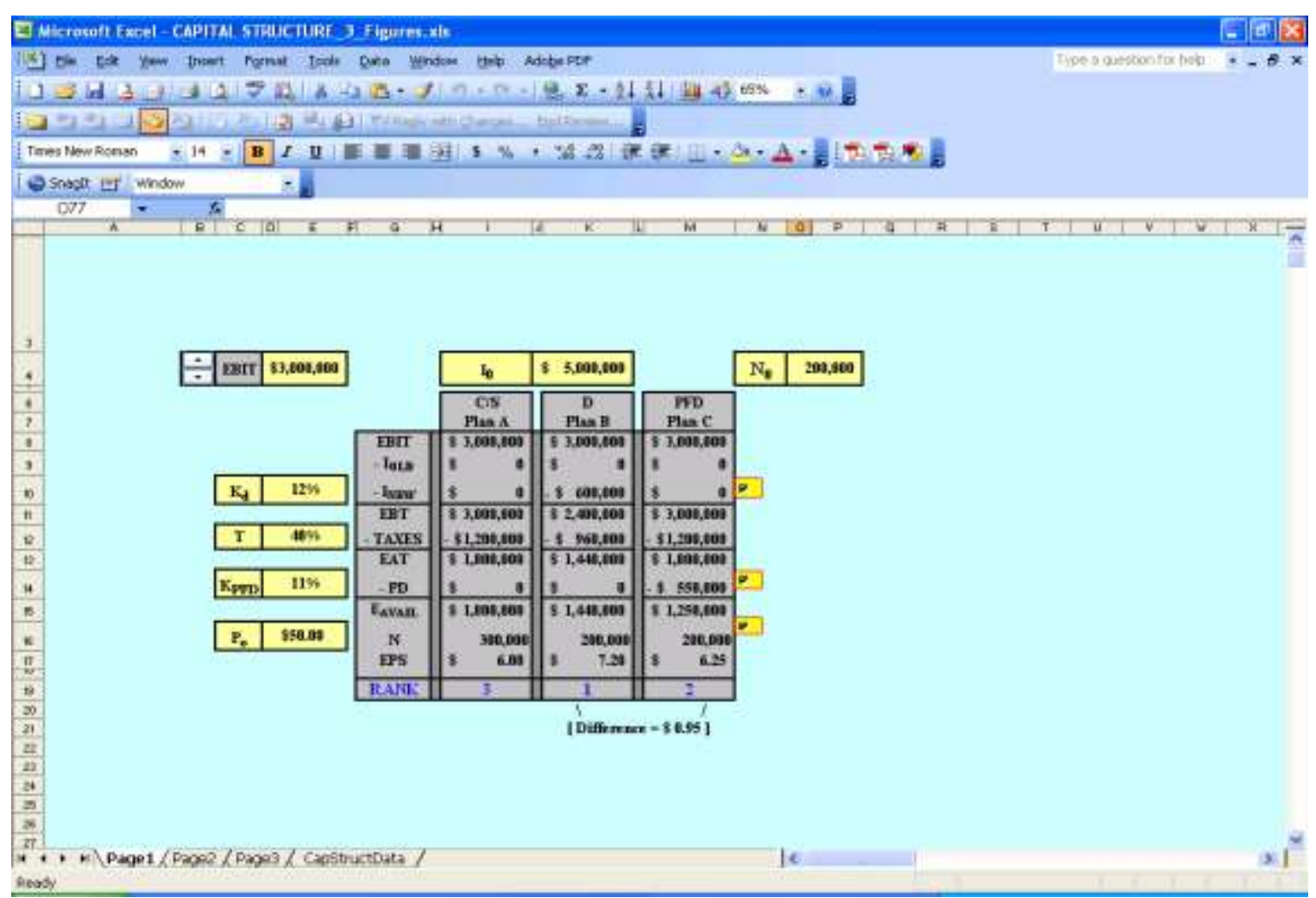

Figure 10

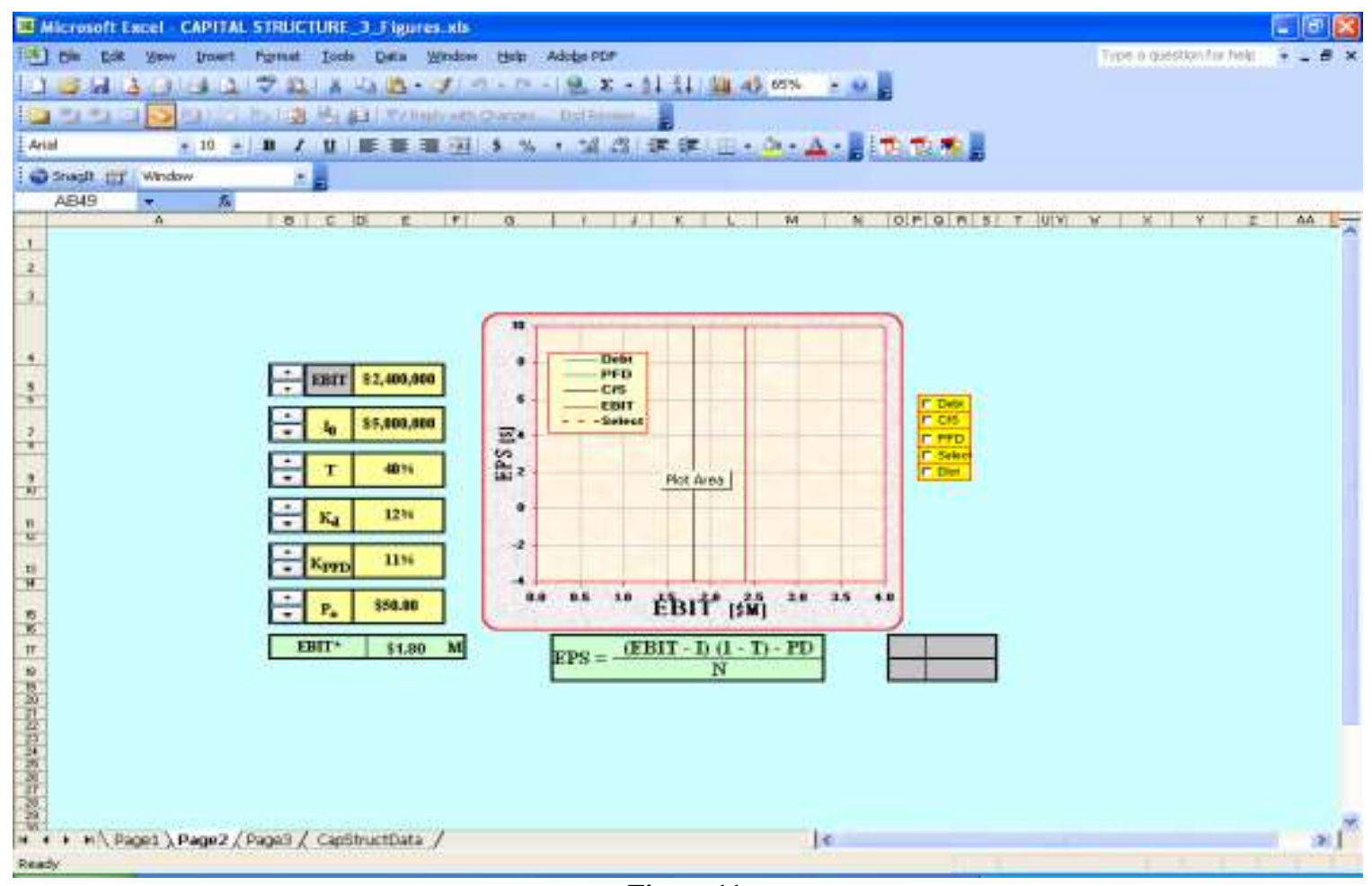

Figure 11 


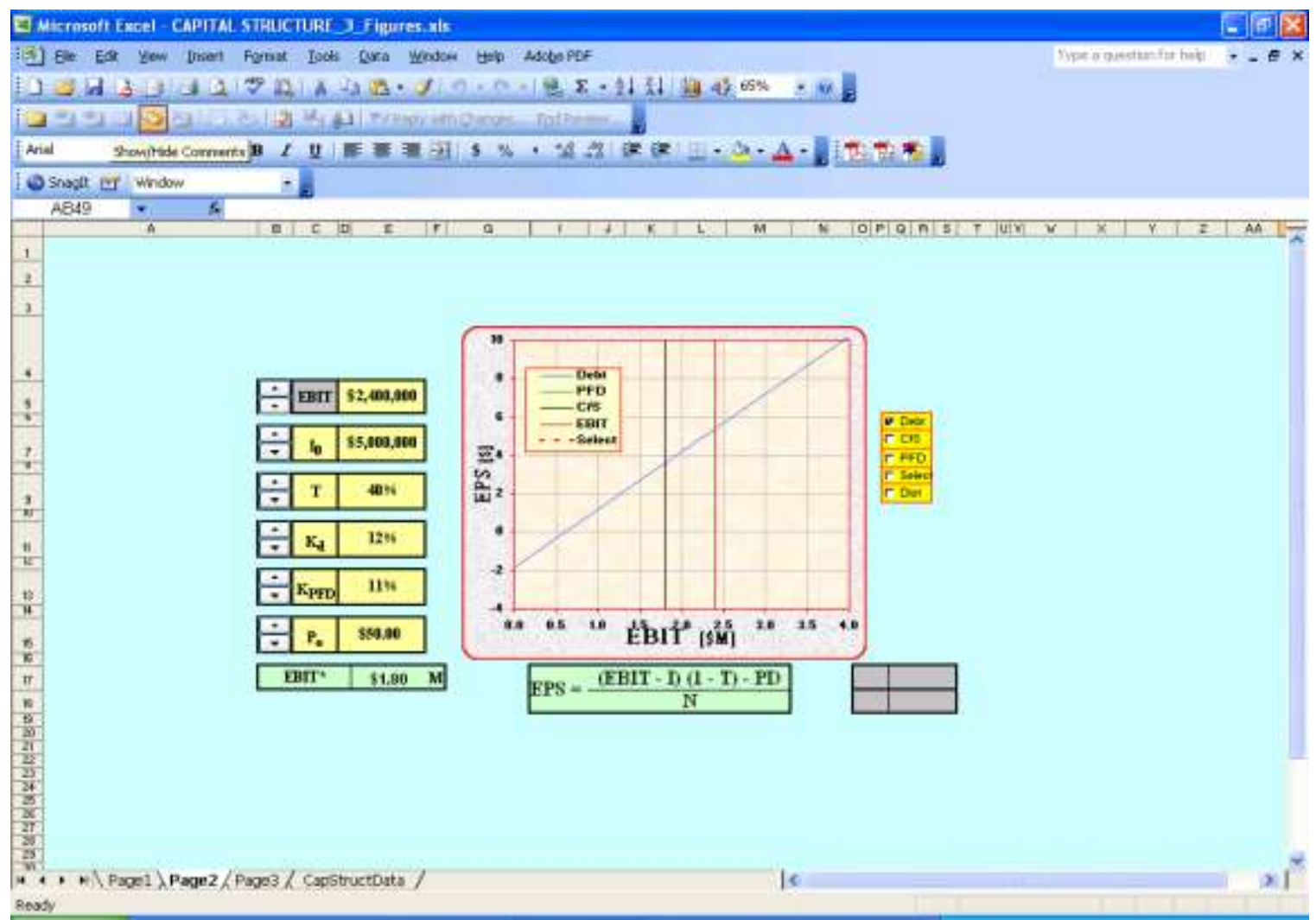

Figure 12

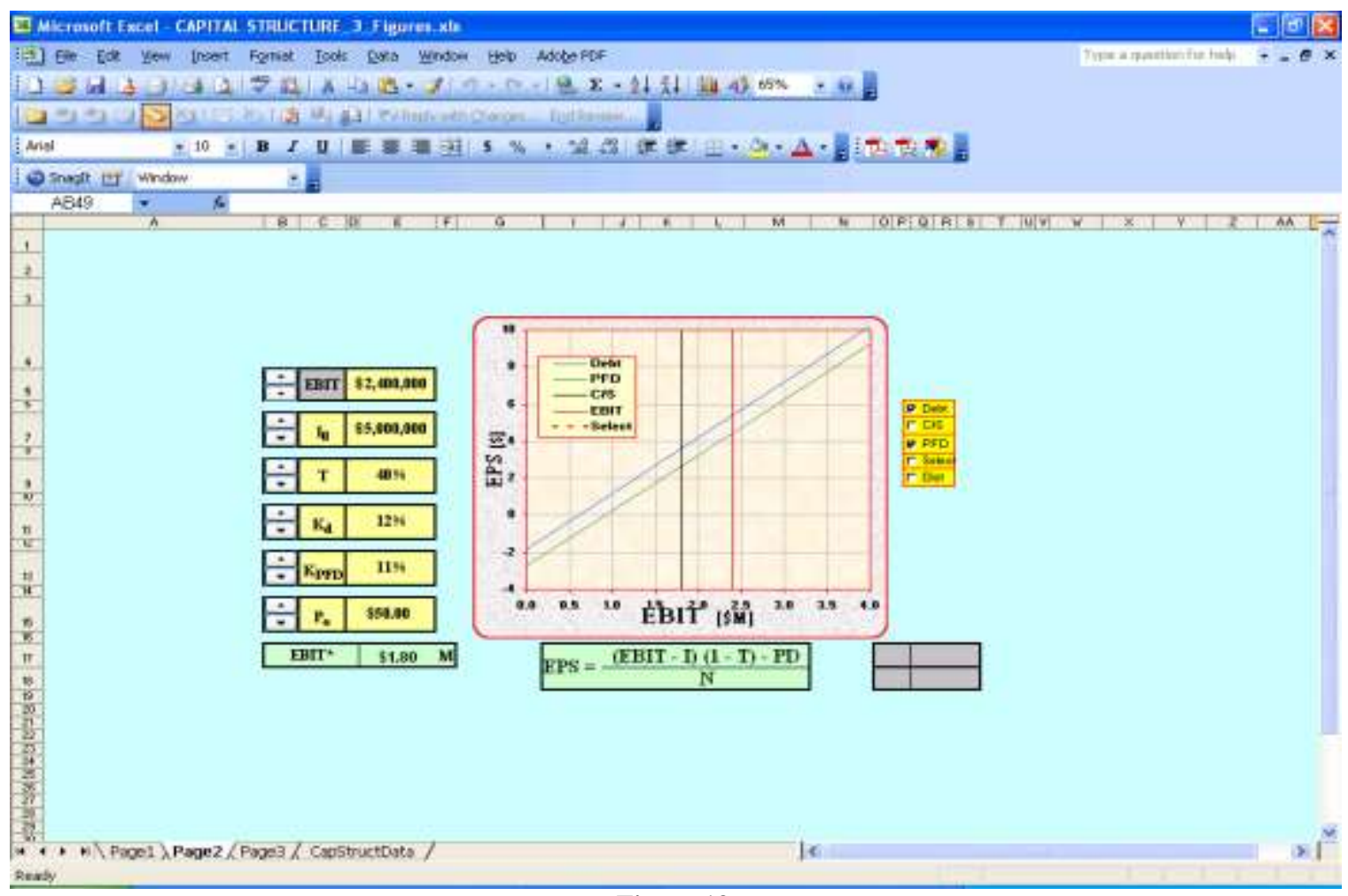

Figure 13 


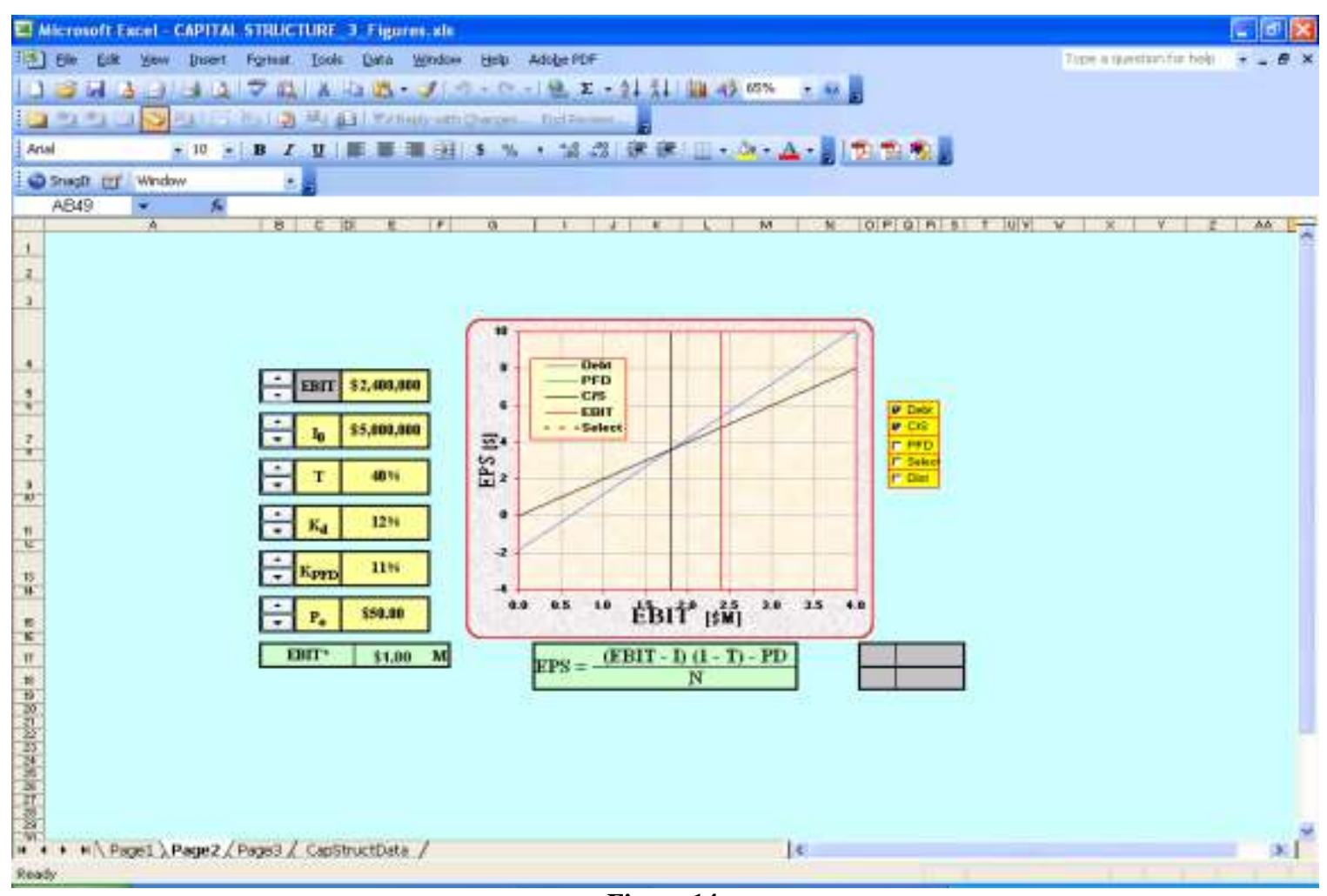

Figure 14

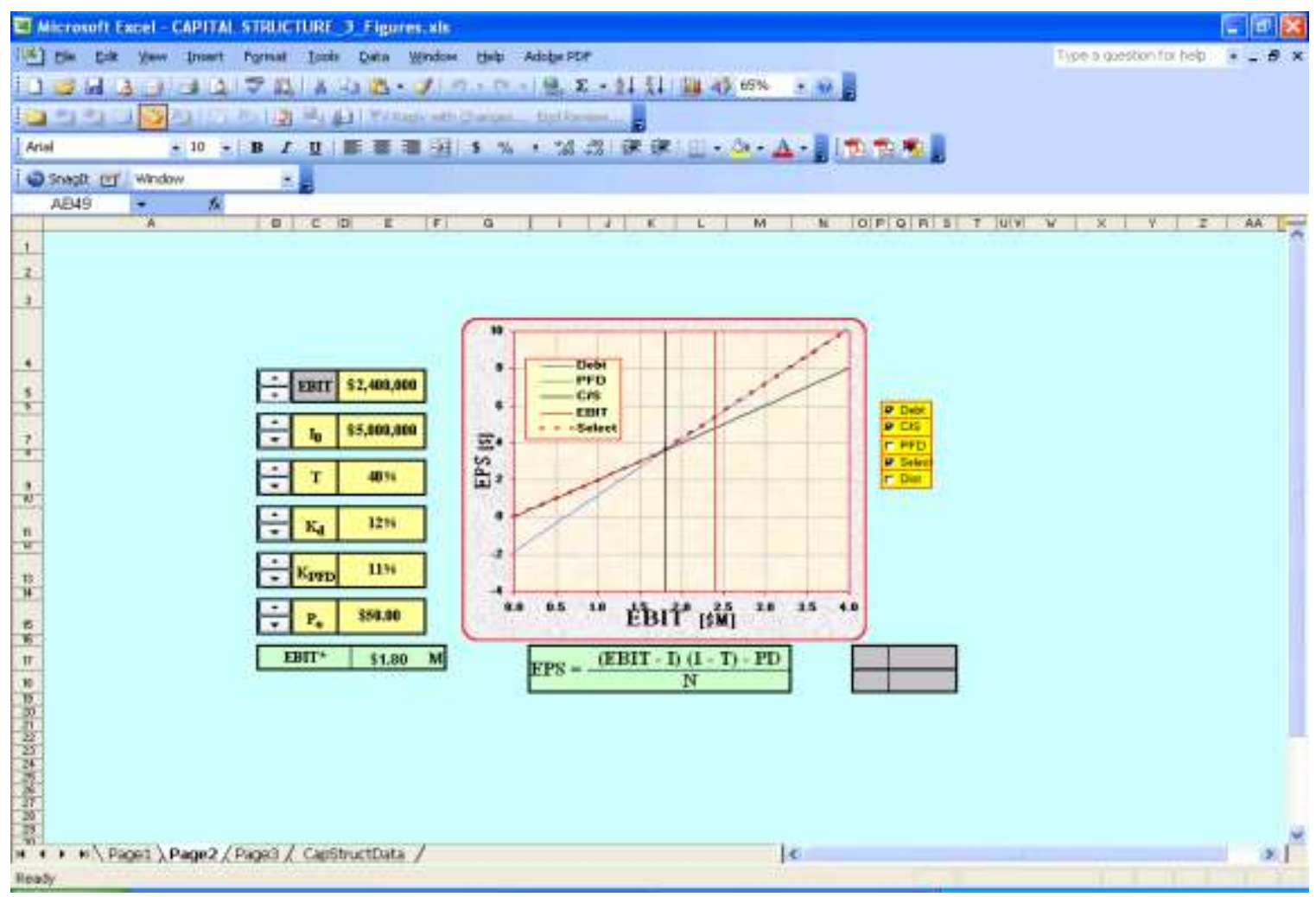

Figure 15 


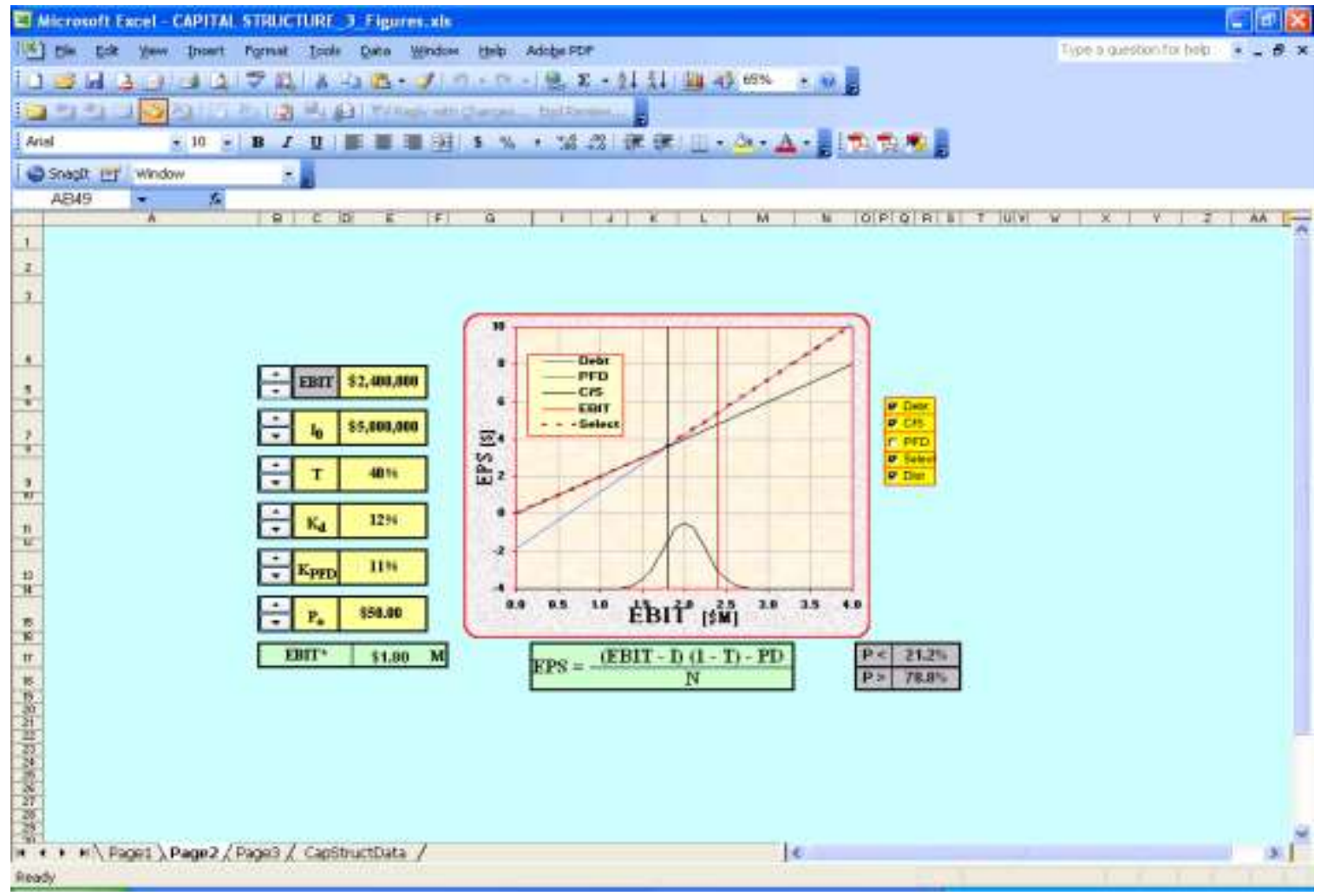

Figure 16 